\title{
The identification of the high risk of metabolic syndrome by applying MDR and Jalview bioinformatics programs
}

\begin{abstract}
The metabolic syndrome (MS) is a complex multi-factorial disease associated with obesity (OB), type 1 diabetes mellitus (DM1), type 2 diabetes mellitus (DM2) and high blood pressure (HBP). This study included 404 subjects selected at Giurgiu Country Hospital, on the basis of clinical evaluation and of biochemical and hematological laboratory investigations, and the sequencing of 28 genes of interest: INS, IGF2, TGF-beta, HSPG Bam H1, ACE, UCP2, FABP2, PLIN1, PON1, FTO, ADRB3, BHMT2, MTHFR, IRS1, TRPM6, MT1A, APOA5, PEMT, ABCB4, CHDH, FADS2, PCYT1A, PCYT1B, PNPLA3, SCD, SCL44A1, STAT3 in identifying the high risk of developing metabolic syndrome. The findings were statistically processed by the MDR and Jalview programs.
\end{abstract}

Keywords: genes, MDR, Jalview, metabolic syndrome
Volume 8 Issue 3 - 2020

\author{
Stanislav Alexandra Alina ${ }^{1,2}$ \\ 'Department of Genetics, University of Bucharest, Romania \\ ${ }^{2}$ Clinical laboratory-Bacteriology, Giurgiu County Emergency \\ Hospital, Romania
}

Correspondence: Stanislav Alexandra Alina, Faculty of Biology, Department of Genetics, University of Bucharest, I-3 Intr. Portocalelor, 06010I, Bucharest 6th District, Romania, Email SAalexy@yahoo.com

Received: April 23, 2020 | Published: June 0I, 2020

\section{Introduction}

The metabolic syndrome (MS) is a complex multi-factorial disease associated with obesity (OB), type 1 diabetes (DM1), type 2 diabetes (DM2) and high blood pressure (HBP). The metabolic and nutritional factors, complemented by the interactions between the genome and the environmental conditions mediated by epigenetic mechanisms, and play important role in the genesis of obesity, diabetes mellitus and high blood pressure. ${ }^{1}$ The purpose of study was to identify the risk of developing $\mathrm{MS}$ in patients diagnosed with obesity (OB), DM1, DM2 and high blood pressure (HBP) by using the MDR and Jalview programs, on the basis of clinical, laboratory (biochemical, hematological) and genetic data.

\section{Experimental section}

The 404 subjects, of whom 219 in patients with MS, OB, DM 2, DM 1, HBP and 185 clinically healthy subjects were enrolled in the study on the basis of their clinical evaluation: age, sex, height, weight, cardiac index, waist circumference, blood pressure, alcoholism, smoking, stress, diet, family history; biochemical laboratory investigations: glucose, triglycerides, HDL, cholesterol, LDL, HbAlc, creatinine, uric acid, urea, TGO, TGP, magnesium, calcium, folic acid, vitamin $\mathrm{D}$, vitamin B12, homocysteine, vitamin $\mathrm{C}$, which were determined by spectrophotometry; and hematological laboratory investigations: WBC, HGB, HCT, RBC. All the subjects were selected at Giurgiu County Emergency Hospital. An informed consent was obtained from all subjects before the commencement of the study. In isolating DNA from blood the DNeasy Blood and Tissue Kit from Qiagen was used $;^{2}$ the spectrophotometric determination of the isolated genomic DNA purity and concentration ${ }^{3}$ and the sequencing of the risk genes were performed by Advanced NGx test. ${ }^{4}$ The statistical analysis was conducted through the following applications: Jalview Software, ${ }^{5}$ MDR Software. ${ }^{6}$ This study was conducted from 20.01.2014-19.01.2015 and 20.01.2015-19.01.2016 as part of a volunteer activity at Giurgiu County Emergency Hospital (Volunteer Contract no 2/20.01.2014 and contract no 2/20.01.2015 subject to art. 13(5) of Law no 677/2001).

\section{Results}

The study included 404 subjects aged 21-92, of whom 219 inpatients diagnosed with MS, OB, DM 1, DM 2, HBP and 185 clinically healthy subjects from the hospital environment. It consisted in sequencing the genes of interest: UCP2, UCP3, FABP2, PLIN1, PON1, FTO, ADRB3, BHMT2, MTHFR, IRS1, TRPM6, MT1A, APOA5, PEMT, ABCB4, CHDH, FADS2, PCYT1A, PCYT1B, PNPLA3, SCD, SCL44A1, STAT3, INS, IGF2, ACE, TGF-beta, HSPG Bam H1 and studying their association with metabolisms in MS. By using the Advanced NGx test it was noted that the dominant homozygous and, respectively the heterozygous form for the adult nutrition included the markers of FADS2 gene associated with omega 6 and omega 3 unsaturated fatty acids (omega 6 and omega 3 are high concentrations );vitamin B2, vitamin B12, betaine, choline, magnesium and folates associated with the following genes: MTHFR, BHMT2, $\mathrm{CHDH}$, PEMT, SLC44A1, TRPM6 (with high concentrations of homocysteine and low concentrations of folic acid, vitamin B12, magnesium, calcium, choline, betaine); genes PEMT, ABCB4, CHDH, FADS2, MTHFR, PCYT1A, PCYT1B, PNPLA3, SCD, SLC44A1, STAT3 are associated with non-alcoholic liver steatosis (with the occurrence of steatosis in overweight or obese individuals); the following genes: UCP2, UCP3, FABP2, PLIN1 were associated with obesity (the occurrence of obesity); genes BHMT2, MTHFR were associated with hyperhomocysteinemia (high concentrations of homocysteine and low concentrations of folic acid, vitamin B12, magnesium, calcium, choline, betaine, riboflavin (vitamin B2), curcumin, fish oil, vitamin $\mathrm{C}$, vitamin $\mathrm{D}$ and vitamin $\mathrm{E}$ ); cholesterol was associated with the following genes: UCP3, UCP2, PON1 (high concentrations of cholesterol, triglycerides, LDL-cholesterol and low concentrations of HDL-cholesterol); the following genes were associated with insulinresistance: IRS1 and TRPM6 (high concentrations of glucose, HbA1c and magnesium); cardiovascular diseases were associated with gene MT1A (high concentrations of glucose and HbAlc); postprandial hyperlipemia was associated with gene APOA5 (high concentrations of cholesterol, triglycerides, LDL-cholesterol and low concentrations of HDL-cholesterol); and other genes associated with physical effort or performance, such as those for the cardiac and respiratory 
function, were associated with genes: SLC16A1, PPARA (high concentrations of cholesterol, triglycerides, LDL-cholesterol and low concentrations of HDL-cholesterol); the muscular function and the body weight were associated with genes: CHDH, FTO, ADRB3, ACE (deficiency of vitamin B12, folic acid, high concentrations of cholesterol, triglycerides, LDL-cholesterol, BMI, height, weight, glucose, HbA1c, systolic and diastolic blood pressure, and low levels of HDL-cholesterol); metabolism was associated with genes: UBE2E2, ADAMTS9-AS2, KLHDC5, IRS1, MEFV, MFE (high concentrations of glucose, cholesterol, triglycerides, LDL-cholesterol and low concentrations of HDL-cholesterol), which are associated with cardiovascular diseases, diabetes, obesity, and can increase the risk for metabolic syndrome.

It was noted that all these genes, with their genetic variations, associated with nutrition in healthy adults, and with lipid, carbohydrate and behavioral metabolism, were associated with a high risk of developing metabolic syndrome (Figures 1-13). After analysis of the secondary structure of the 28 genes of interest, it was noted that those genes, through the sequence of nucleotides preserved in position 1 , were associated with the metabolic syndrome, by using Jalview 2.8 software.

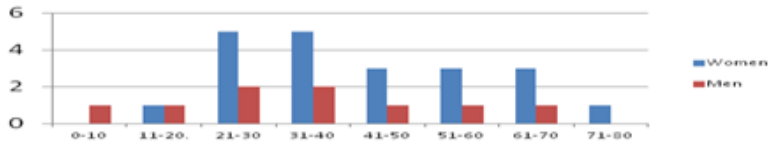

Figure I Distribution of the patients' number according to sex and age.

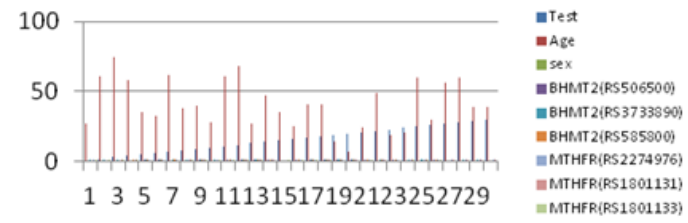

Figure 2 Markers associated with hyperhomocysteinemia.

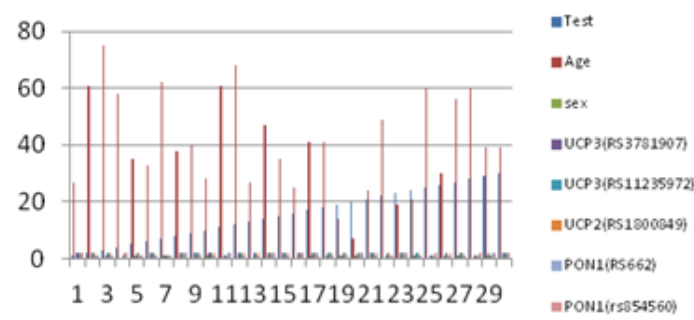

Figure 3 Markers associated with cholesterol.

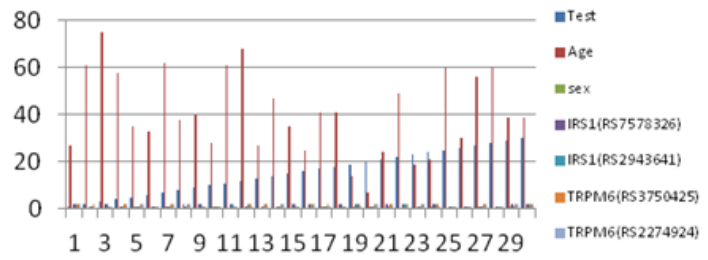

Figure 4 Markers associated with DM 2/ insulin-resistance.

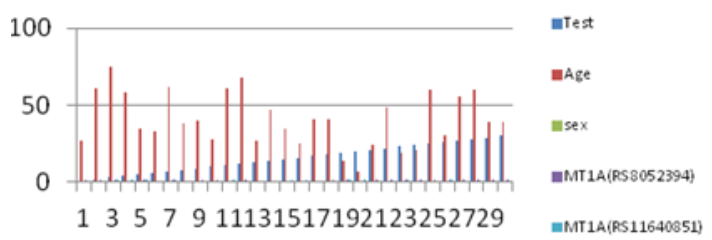

Figure 5 Markers associated with cardiovascular disease in the elderly.

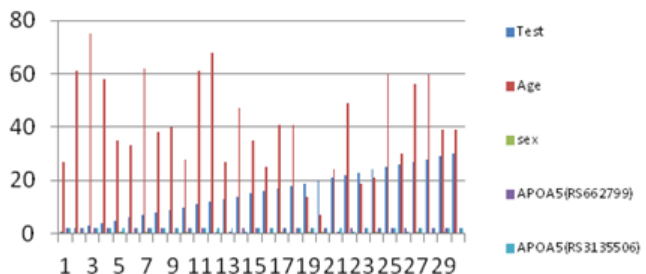

Figure 6 Markers associated with postprandial hyperlipemia.

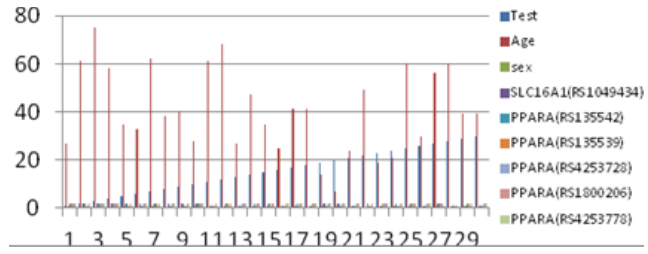

Figure 7 Markers associated with the heart, vascular and respiratory functions.

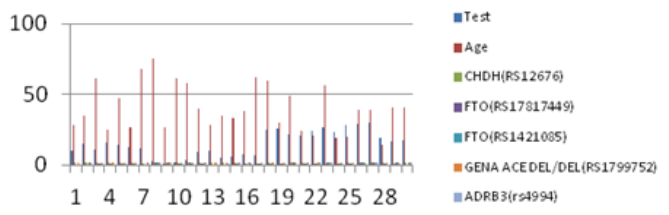

Figure 8 Markers associated with the muscular function and body weight.

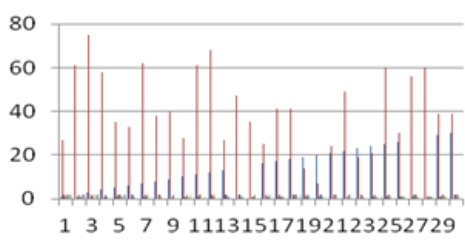

me Te

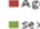

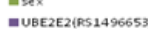
=ADAMTS9-AS21056795735 $=$ KLHOCS(PS 10842994 $=$ IPS1(PS 2943640) IIEFV(RS28940578) MFEERS 1799945) $=$ HFE (PS518007 30)

Figure 9 Markers associated with metabolism

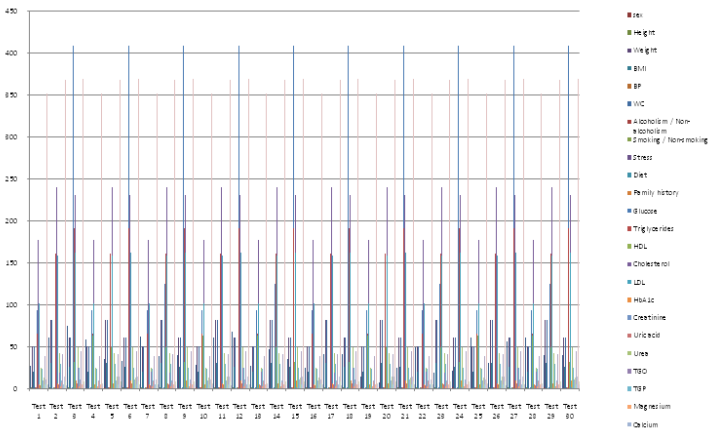

Figure 10 Clinical and laboratory results.

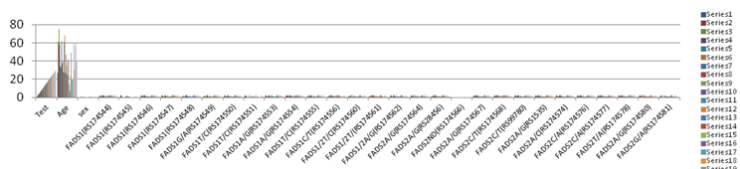

Figure II Markers and genes associated with omega 6 and omega 3 unsaturated fatty acids.

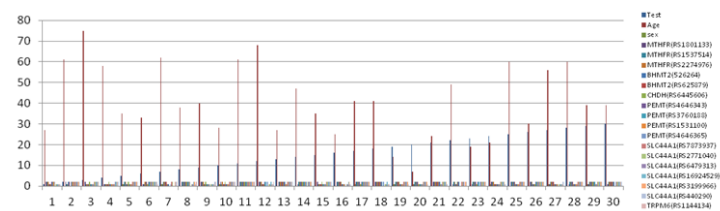

Figure 12 Markers associated with the metabolism of vitamin B2, vitamin $\mathrm{BI}$ 2, betaine, choline, magnesium and folates. 


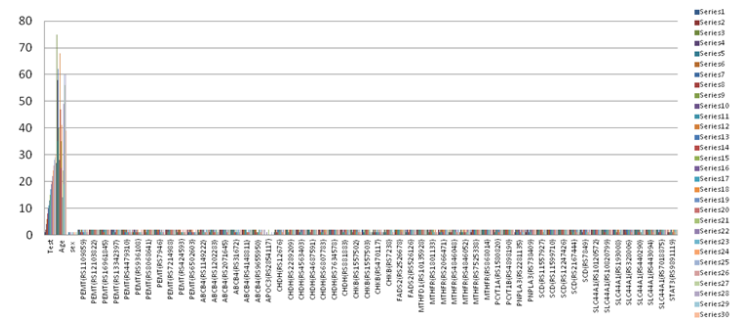

Figure 13 Markers associated with non-alcoholic fatty liver.

The statistical analysis performed by applying the MDR software version 3.0.2. revealed that, in the whole set of clinical data, laboratory investigations and genes of interest investigated by Advanced NGx, OR was the highest, $\mathrm{OR}=104.7455, \mathrm{OR}>1$, which results in a high risk of developing metabolic syndrome (Figure 15). The Jalview 2.8 software was used to identify the secondary structure of genes UCP2, UCP3, FABP2, PLIN1, PON1, FTO, ADRB3, BHMT2, MTHFR, IRS1, TRPM6, MT1A, APOA5, PEMT, ABCB4, CHDH, FADS2, PCYT1A, PCYT1B, PNPLA3, SCD, SCL44A1, STAT3, INS, IGF2, ACE, TGF-beta, HSPG Bam H1. It was noted that the amino acid composition of the 28 genes was preserved and identical in position 1 of the nucleotide sequence. The phylogenetic tree was obtained by the Neiber Joining method. It was noted that genes PNPLA3, UCP3, HSPG, TRPM6 are phylogenetically related and they are composed of more sequences of common amino acids. FADS2, PON1, PLIN1, PCYT1A, PCYT1B, IRS1 are phylogenetically related and they are composed of fewer sequences of common amino acids. $\mathrm{CHDH}$ is phylogenetically related, but the amino acid sequences are different. APOA5, INS are phylogenetically close but the amino acid sequences are identical. UCP3, MTHFR, STAT3, TRPM6 are phylogenetically related, but they are different in sequences of common amino acids. MT1A, ADRB3, IRS1 are phylogenetically related and they are close in the common amino acid sequences. IGF2, ADRB3, TGFB, SCD, PNPLA3, FTO are phyolgenetically close and they are different in the common sequences of amino acids. ACE, INS, PEMT, SLC44A1, FABP2, UCP2, BHMT2 are phylogenetically related and they are similar in sequences of common amino acids. The genes were associated with the metabolic syndrome, obesity, diabetes mellitus and high blood pressure (Figures 14, 16).

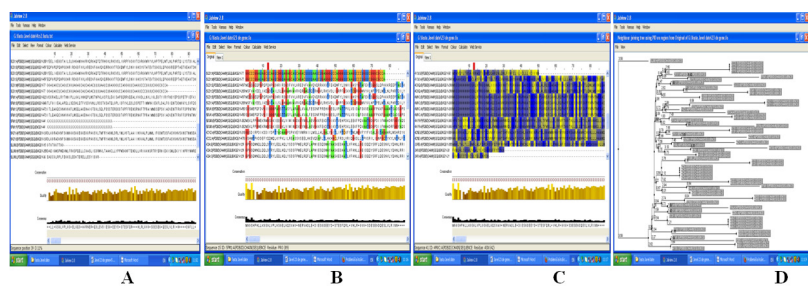

Figure 14 A) Fasta format; B) Secondary structure; C) Composition of nucleic acids; D) Representation of the phylogenetic trees of genes UCP2, UCP3, FABP2, PLINI, PONI, FTO, ADRB3, BHMT2, MTHFR, IRSI, TRPM6, MTIA, APOA5, PEMT, ABCB4, CHDH, FADS2, PCYTIA, PCYTIB, PNPLA3, SCD, SCL44AI, STAT3, INS, IGF2, HSPG, TGFb, ACE. PDB processed in Jalview program.

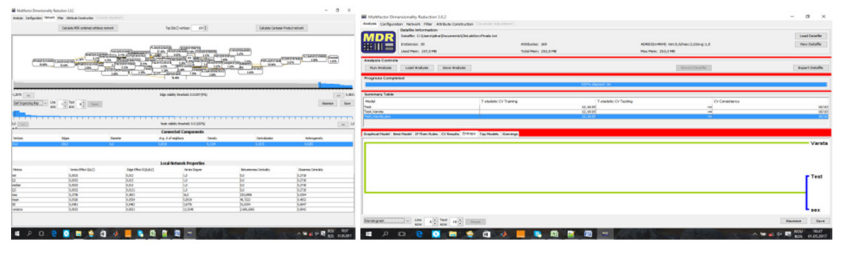

A

B

Figure 15 A) Graphic interaction model for MS, OB, DMI, DM2, HBP. B) Cluster by dendogram generated by MDR .

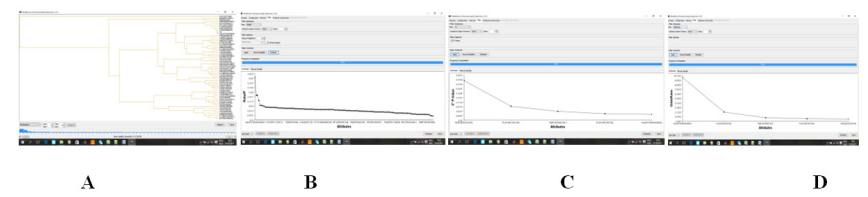

Figure I6 MDR data processing evaluated through $(A)$ the dendogram provided by MDR c, (B) Relief F, (C) Val P, (D) OR.

The 28 genes were associated with cardiovascular diseases, diabetes, obesity, which generates a high risk of metabolic syndrome. The Jalview 2.8 processing of the nucleotide sequences of the examined set of genes allowed the identification of secondary structure modifications in the corresponding proteins, which provides the premises for their association with possible functional alterations. The building of the phylogenetic tree by Jalview showed that the 28 genetic markers were associated with an increased risk of MS. The graphical model, the interaction map and the cluster obtained by applying MDR confirm that the polymorphisms of the 28 genes present an increased risk of MS. ReliefF $=0,45$, Value $\mathrm{P}=0,00001(\mathrm{p}<0,0001)$, OR $=104.7455, \mathrm{OR}>1$.

The application MDR was chosen to include all the investigated data: clinical, laboratory and genetic data for the identification of increased risk of MS.

a. This is the first study in Romania which correlated extremely diverse (clinical, biochemical, hematological, genetic) parameters by applying several techniques, including molecular (NGS sequencing).

b. For maximum accuracy of the correlations between the investigated data, complex sets of statistical and mathematical modelling programs were used: Jalview, MDR.

c. With a view to the development of personalized medicine programs, the information provided in this article is of major importance in implementing complex methods of individual assessment of the MS risk and of associated diseases nutritional management.

\section{Discussion}

Information about the investigated genes can be found in the published literature.

INS (insulin) gene. Cytogenetic location: $11 \mathrm{p} 15.5 .^{7}$ It plays an important role in producing insuline, which is necessary for the control of blood glucose. ${ }^{8}$ The genetic variant of insulin gene (VNTR and SNP) plays a role in the susceptibility to type 1 and type 2 diabetes mellitus. INS gene is associated with the metabolic syndrome, ${ }^{9}$ type 2 dibetes mellitus, polycystic ovary syndrome and coronary diseases. ${ }^{10}$

IGF2 gene (insulin-like growth factor 2). In humans, IGF2 gene is located on chromosome $11 \mathrm{p} 15.5$ in the region containing numerous imprinted genes. ${ }^{11}$ IGF2 is a regulator of somatic growth, cell proliferation and maternal imprinting (imprinting of the telomeric domain of region $11 \mathrm{p} 15$ containing silenced hypermetilated ASCL2, H19 and IGF2 in Wilms tumors). ${ }^{12}$ It is involved in stem cell differentiation. ${ }^{13}$ IGF2 influences placental lactation and can play a role in fetal development. ${ }^{14}$ The synthesis of several specific components such as proteoglycans and other components of the connective matrix. Using a feedback mechanism, it inhibits the release of the growth hormone (while stimulting the release of somatostatin). ${ }^{15}$ IGF2 acts as a growth factor and predisposes to diabetes mellitus. IGF2 gene is associated with obesity, type 2 diabetes mellitus ${ }^{16}$ and gestational diabetes. ${ }^{17}$ 
TGF-beta (Transforming growth factor beta) gene. Cytogenetic location : 19q13.1. TGF-beta fulfills important roles: it stimulates tissue repair and fibrosis by regulating cell proliferation and apoptosis and by synthetising components of the extracellular matrix; it participates in regulating the function of the immune system; it inhibits the functioning of $\mathrm{T}$ and $\mathrm{B}$ lymphocytes, the proliferation of neurons, of endothelial and mesenchymal cells, the synthesis of several cytokines $;{ }^{18}$ it plays a role in growth control, inflammation and tumorigenesis. ${ }^{19}$ TGF-beta gene was associated with type 2 and type 1 diabetes mellitus, ${ }^{20}$ obesity, diabetes mellitus, high blood pressure ${ }^{19}$ and $\mathrm{MS}^{21}$

HSPG (Heparan sulfate proteoglycans) gene. Cytogenetic location : 1p36.1-p34. It plays an important role in maintaining the glomerular ultrafiltration barrier and in reducing density. It can contribute to the initiation of albuminuria and to the alteration of the renal function in patients suffering from type 1 diabetes mellitus. It has a role in the endothelial dysfunction and in improving capillary permeability. ${ }^{18}$ In vivo studies showed that HSPG has several cellular functions and is essential in development, that is why it is involved in the regulation of signalling pathways, transforming growth factor $\beta$ and fibroblast growth factor pathways. ${ }^{22}$ It helps maintain vascular homeostasis and can participate in the activation of FGF2, by stimulating endothelial growth and regeneration, ${ }^{23}$ it also plays a role in lipoprotein metabolism. ${ }^{24}$ Polymorphism is associated with diabetes mellitus and HSPG (Heparan sulfate proteoglycans). ${ }^{18}$

ACE (Angiotensin-Converting Enzyme) gene. Cytogenetic location: 17q23.3. ACE plays an important role in regulating blood pressure, ${ }^{25}$ and in the conversion of (inactive) angiotensin I decapeptide to (active) angiotensin II octapeptide. ${ }^{26} \mathrm{~A}$ role in pulmonary infections caused by coronaviruses is held by ACE ID polymorphism, which is consedered to be involved in the spread of SARS-CoV-19 among European populations. ${ }^{27}$ ACE ID polymorphism is associated with cardiovascular diseases, diabetes mellitus, diabetic nephropathy, aterosclerosis, heart diseases and stroke, high blood pressure, obesity, Alzheimer disease, cancer and Parkinson disease (DD genotype), while II genotype has also a strong effect in longevity. ${ }^{26}$ It was reported that ACE2 deficiency in the mouse, which encodes an essential regulating enzyme of the renin-angiotensin system (RAS) results in a very high susceptibility in the epithelial lesion-induced intestinal inflammation. RAS is involved in acute pulmonary insufficiency, cardiovascular functions and SARS infections. ${ }^{28}$ ID polymorphism in intron 16 of ACE1 is associated with modifications of ACE circular and tissue concentrations. SARS-CoV and SARS-CoV-2 can bind to target cells via ACE2 whihg facilitates quick viral replication, while in the lungs, the depletion of ACE2 from the cell membrane improves the damaging effects of Ang II. ${ }^{29}$

FTO (Fat mass and obesity-associated) gene. Cytogenetic location: $16 q 12,2$. FTO gene plays a role in obesity; through the generation of new fat cells or adipocytes, a process called adipogenesis, this gene acts on the key processes occurring in the first stages of adipogenesis. ${ }^{30}$ It is also involved in nutrient detection and translation and growth regulation. ${ }^{31}$ FTO is associated with type 2 diabetes mellitus and cardiovascular disease, ${ }^{32}$ obesity, cancer, hypertension, Alzheimer disease and renal impairment ${ }^{33}$ and with MS. ${ }^{34}$

ADRB3 (Beta-Adrenergic Receptors 3) gene. Cytogenetic location: 8p11.23. ADRB3 gene has a role in lipid metabolism ${ }^{35}$ and in the regulation of the energy balance. ${ }^{36}$ The polymorphism of gene ADRB3, Trp64Arg, is associated with obesity, diabetes mellitus and hypertension, ${ }^{37}$ metabolic obesity ${ }^{38}$ and MS. ${ }^{39}$
UCP2 (uncoupling protein 2) gene. Cytogenetic location: 11q13.4. UCP2 is involved in thermogenesis, obesity, diabetes mellitus and atherosclerosis, as well as in the control of the reactive oxygen species derived from mitochondria (Vidal-Puig et al., 1997). It also plays a role in ageing, as a source of amino acid, as cellular response to starvation, as cellular response to glucose stimulus, as cellular response to insulin stimulus, in pregnancy, liver regeneration, negative regulation of apoptosis, negative regulation of insulin secretion, ${ }^{40}$ in lipid metabolism (Pecqueur et al., 2009). UCP2 was associated with obesity, ${ }^{41}$ type 2 diabetes mellitus. ${ }^{42}$ It plays a role in the metabolic syndrome and in the development of type 2 diabetes mellitus. ${ }^{43}$

UCP3 (uncoupling protein 3) gene. Genomic location: 11q13.4. ${ }^{44}$ UCP3 can participate in the modulation of the respiratory control of tissues ${ }^{40}$ in thermogenesis, ${ }^{44}$ in the outward translocation of fatty acids from the mitochondrial matrix. ${ }^{45} \mathrm{UCP} 3$ is associated with severe obesity ${ }^{46}$ and type 2 diabetes mellitus. ${ }^{47}$

FABP2 (Fatty acid binding protein 2) gene. Genomic location: $4 q 28-q 31 . F A B P 2$ is involved in the improvement of the intracellular enzyme hypofunction caused by long-chain fatty acids. It acts as a free radical scavenger or it removes peroxidized acids from cells. ${ }^{48}$ FABP2 is probably involved in the lipoprotein and triglyceride synthesis and can help maintain functional energy homeostasis as a lipid sensor; it responsible for the modulation of cell growth and proliferation. ${ }^{49}$ IFABP can be involved in the absorption of fatty acids from the intestinal lumen and the transport of intestinal enterocytes to organs,$^{50}$ in the intercellular absorption and transport of dietary longchain fatty acids. ${ }^{51} \mathrm{FABP} 2$ gene is associated with MS, ${ }^{52}$ with type 2 diabetes mellitus ${ }^{53}$ and high blood pressure. ${ }^{54}$

PLIN1 (Perilipin 1) gene. Cytogenetic location: 15q26.1. PLIN1 gene controls the storage and release of fats into adipocytes $;{ }^{55}$ it acts as a modulator of lipid metabolism in adipocytes. ${ }^{56}$ PLIN1 is associated with insulin-dependent diabetes mellitus (IDDM3), ${ }^{57}$ with obesity, ${ }^{58}$ cardiovascular disease ${ }^{59}$ and metabolic syndrome. ${ }^{60}$

PON1 (paraoxonase/arylesterase 1) gene. Cytogenetic location: 7q21.3. It is responsible for the hydrolysis of organophosphorus pesticides and toxic fumes acting on the nervous system; it plays a role in the innate immunity and healthy ageing. However, this mechanism is yet unknown. ${ }^{61}$ It participates in lipid peroxidation, detoxification of reactive molecules, modulation of endoplasmic reticulum stress and regulation of cell proliferation/apoptosis. ${ }^{62}$ PON1 gene is associated with coronary diseases,${ }^{63}$ diabetes and amyotrophic lateral sclerosis ${ }^{49}$ type 1 diabetes mellitus ${ }^{64}$ insulin resistance and metabolic syndrome,${ }^{65}$ type 2 diabetes mellitus and its complications, ${ }^{66}$ and high blood pressure. ${ }^{67}$

BHMT2 (Betaine homocysteine methyltransferase 2) gene. Cytogenetic location: $5 \mathrm{q} 14.1{ }^{68}$ BHMT2 is involved in the regulation of homocysteine metabolism. ${ }^{40}$ It is associated with cardiovascular disease, osteoporosis, dementia and pregnancy complications, ${ }^{69}$ coronary artery disease, stroke and venous thrombosis. ${ }^{70}$

MTHFR (5,10-Methylenetetrahydrofolate reductatse) gene. MTHFR is located on chromosome 1p36.3. ${ }^{71}$ MTHFR enzyme plays an important role in the processing of amino acids and blocks of proteins..$^{72}$ The epigenetic functions of the methyl group are the following: to protect DNA and RNA against the action of viruses, bacteria, heavy metals, solvents and other toxins in the environment; to lower histamin levels; to protect cell membranes. ${ }^{73}$ It participates in the formation and maturation of RBC (red blood cells), leucocytes (white blood cells) and in the production of thrombocytes. ${ }^{74}$ MTHFR 
is associated with cardiovascular diseases, ${ }^{75} \mathrm{HBP}$ and mental retardation ${ }^{76}$ and MS. ${ }^{77}$ The American Diagnosis and Statistical Manual of Mental Disorders (DSM-5) contains a number of criteria for the classification of mental disorders: dementia (BHMT2 gene), mental retardation (MTHFR gene), degenerative diseases: Alzheimer, which is caused by genetic mutations in persons with a family history and Parkinson (ACE gene). ${ }^{78}$ It aimed to involve ACE/MTHFR genotypes in a wider algorithm of genes which influence $\mathrm{CVD} /$ diabetes, obesity, along with the gene which the literature considers as critical in Alzheimer disease-ApoE. ApoE4 poses a high risk of developing late-onset Alzheimer disease and cardiovascular diseases. ${ }^{79}$

IRS1 (insulin receptor substrate 1) gene. Cytogenetic location: $2 q 36.3$. IRS1 is involved in insulin signaling, maintaining basic cell functions, such as: growth, survival, metabolism. ${ }^{80}$ IRS1 is associated with IR syndrome, atherosclerotic cardiovascular diseases associated with type 2 diabetes mellitus, ${ }^{81} \mathrm{HBP}^{82}$ and MS. ${ }^{83}$

TRPM6 (Transient Receptor Potential Cation Channel Subfamily M Member 6) gene. Cytogenetic location: 9q21.13. ${ }^{84}$ TRPM6 has an important role in epithelial magnesium transport and the absorption of active magnesium in the gut and kidneys. ${ }^{49}$ TRPM6 is associated with metabolic disorders and associated chronic diseases such as oxidative stress, systemic inflammation, endothelial dysfunction, insulin resistance, HBP, type 2 diabetes mellitus and coronary disease ${ }^{84}$ diabetes mellitus, ${ }^{85}$ gestational diabetes mellitus. ${ }^{86}$

MT1A (Metallothionein 1A) gene. Cytogenetic location: 16q13. Metallothioneins participate in the zinc and copper metabolisms and can be involved in neutralizing free radicals ${ }^{87}$ and protecting against reactive oxygen species. ${ }^{88}$ MT1A is associated with type 2 diabetes mellitus and CVD,${ }^{89} \mathrm{HBP}$, MS and obesity. ${ }^{90}$

APOA5 (Apolipoprotein A5) gene. Cytogenetic location: 11q23.3. APOA5 participates in determining plasmatic levels of triglycerides in an age-independent manner. ${ }^{91}$ It is associated with obesity and metabolic syndrome, ${ }^{91} \mathrm{HBP}^{93}$ and DM2. ${ }^{94}$

PEMT (Phosphatidylethanolamine N-Methyltransferase) gene. Cytogenetic location: 17p11.2. The CDP-choline pathway participates in obtaining choline from diet, through lipid metabolism. The PEMT pathway was shown to have a critical role in supplying PC during periods of starvation. PC, via PEMT, plays numerous physiological roles: cholin synthesis, hepatocyte membrane structure, bile secretion and very low-density lipoprotein secretion. The binding site in the region of PEMT promoter may increase the risk of liver steatosis an estrogen choline deficiency. ${ }^{95}$ PEMT is associated with liver disorders ${ }^{96}$ and with DMZ. ${ }^{97}$

ABCB4 (ATP Binding Cassette Subfamily B Member 4) gene. Cytogenetic location: 7q21.12. This gene plays a role in the metabolism and homeostasis of glucose $;^{98}$ it protects hepatocytes against the damaging activity of bile salts ${ }^{56}$ participates in recruiting phosphatidylcholine (PC), phosphatidylethanolamine (PE) and sphingomyelin molecules (SM); ${ }^{40}$ in bile formation, as a transporter of bile salts, it mediates the ATP-dependent lipid efflux and excretes phosphatidylcholine and cholesterol in the presence of bile salts; ${ }^{99}$ it participates in the transport of phospholipids from hepatocytes into the bile. ${ }^{100} \mathrm{ABCB} 4$ is associated with severe liver diseases, ${ }^{101}$ liver steatosis, ${ }^{102}$ non-alcoholic fatty liver disease and obesity. ${ }^{103}$

CHDH (choline dehydrogenase) gene. Cytogenetic location: 3p21. ${ }^{104}$ $\mathrm{CHDH}$ is involved in physiological processes and aterogenesis. ${ }^{105} \mathrm{It}$ is associated with $\mathrm{CVD},{ }^{106}$ type 2 diabetes mellitus and obesity. ${ }^{107}$
FADS2 (Fatty acid desaturase 2) gene. Cytogenetic location: 11q12.2. ${ }^{108}$ FADS2 participates in fatty acid metabolism via its PPAR signalling pathways, alpha-linoleic acid (omega 3) and linoleic acid (omega 6). ${ }^{49} \mathrm{FADS} 2$ is associated with type 2 diabetes mellitus, CAD, MS, myocardial infarction and dyslipidemia, ${ }^{109}$ and with MS. ${ }^{110}$

PCYT1A (Phosphate cytidylyltransferase 1, choline, alpha) gene. Cytogenetic location: 3q29. PCYT1A is involved in the normal functioning of fatty tissue and insulin action, ${ }^{111}$ and in the control of phosphatidylcholine synthesis. ${ }^{112}$ PCYT1A is associated with severe fatty liver, DM and steatosis. ${ }^{113}$

PCYT1B (Phosphate cytidylyltransferase 1, choline, beta) gene. Cytogenetic location: Xp22.11. PCYT1B participates in the control of phosphatidylcholine biosynthesis and in the suppression of the growth of calcium oxalate $(\mathrm{CaOx})$ crystals. ${ }^{114}$ PCYT1B is associated with CVD, DM, HBP and MS. ${ }^{115}$

PNPLA3 (Patatin like phospholipase domain containing 3) gene. Cytogenetic location: 22q13.31.116 The normal function of PNPA3 provides instructions to a protein called adiponutrin, which can be found in fat cells (adipocytes) and liver cells (hepatocytes). The function of adiponutrin is not well known, but it is believed to help the regulation of adipocyte development, the fat production and decomposition (lipogenesis and lipolysis) in hepatocytes and adipocytes $; 8$ it may be involved in the energy balance of adipocytes. ${ }^{116}$ PNPLA3 is associated with a whole range of non-alcoholic fatty liver lesions: steatohepatitits, cirrhosis and hepatocellular carcinoma (HCC), chronic viral hepatitis, alcoholic liver disease, haemochromatosis, ${ }^{117}$ obesity, liver steatosis, ${ }^{118}$ NAFLD, MS and type 2 diabetes mellitus. ${ }^{119}$

SCD (Stearoyl-CoA desaturase) gene. Cytogenetic location: $10 \mathrm{q} 24.31 .{ }^{120} \mathrm{SCD} 1$ plays an important role in the lipid metabolism. ${ }^{121}$ SCD is associated with CVD, obesity, non-insulin-dependent diabetes mellitus, HBP, neurological diseases, immune system disoders and cancer, ${ }^{121}$ type 2 diabetes mellitus and MS. ${ }^{122}$

SLC44A1 (Solute Carrier Family 44 Member 1) gene. Cytogenetic location: 9q31.2. SLC44A1 acts as a choline transporter in the central nervous system. ${ }^{123}$ It participates in membrane synthesis and myelin production. ${ }^{24}$ SLC44A1 is associated with liver steatosis, MS and type 2 diabetes mellitus. ${ }^{125}$

STAT3 (Signal Transducer And Activator Of Transcription 3) gene. Cytogenetic location: 17q21.2. ${ }^{126}$ The transcription factor STAT3 is constitutively active in many types of cancer, where it mediates important biological effects, including cell proliferation, differentiation, survival and angiogenesis. The N-terminal domain of STAT3 fulfills multiple functions, such as cooperative DNA binding, nuclear translocation. ${ }^{127}$ STAT3 gene is associated with fatty liver diseases, ${ }^{126}$ MS and abdominal obesity. ${ }^{128}$

UBE2E2 (Ubiquitin Conjugating Enzyme E2 E2) gene is located on chromosome $3 \mathrm{p} 24.3 .^{49}$ It participates in insulin secretion and synthesis. It is associated with type 2 diabetes mellitus ${ }^{129}$ and MS. ${ }^{130}$

ADAMTS9-AS2 (RNA gene ADAMTS9-Antisense RNA2) gene is located on chromosome $3 \mathrm{p} 14.1 .^{49}$ It is involved in the inhibition of the proliferation and migration of non-small cell lung cancer cells(NSCLC) and in renal cell carcinoma(RCC). ${ }^{131}$ It is associated with type 2 diabetes mellitus and obesity. ${ }^{132}$

KLHDC5 (Kelch Domain-Containing Protein 5) gene is located on chromosome $12 \mathrm{p} 11.22$. It plays a role in the microtubule dynamics during mitosis. ${ }^{49}$ It is associated with type 2 diabetes mellitus, obesity and metabolic syndrome. ${ }^{133}$ 
MEFV(Mediterranean fever sau Pyrin Innate Immunity Regulator) gene. It is located on chromosome 16p 13.3. ${ }^{49}$ It is involved in the abnormal purine synthesis, to prevent the effects of suppression and inflammation. It is associated with MS. ${ }^{134}$

HFE (Homeostatic iron regulator) gene. It is located on chromosome $6 \mathrm{p} 22.2 .{ }^{49}$ It is involved in the absorption of circulating iron via the regulation of the interaction of transferrin receptor with tranferrin. ${ }^{135}$ This gene is associated with type 2 diabetes mellitus and MS. ${ }^{136}$

PPARA (Protein Coding, Peroxisome Proliferator Activated Receptor Alpha) gene. It is located on chromosome $22 \mathrm{q} 13.31 .{ }^{49}$ It is involved in the regulation of carbohydrate and lipid metabolism. This gene is associated with MS and type 2 diabetes mellitus. ${ }^{137}$

SLC16A1 (Solute carrier family 16 member 1) gene. It is located on chromosome 1p13.2. ${ }^{49}$ It participates in the energy (glucose) supply, particularly in the brain, which is not able to use fatty acids directly. ${ }^{138}$ This gene is associated with MS and obesity. ${ }^{139}$

Advanced NGx test uses the sequencing method, which allows several iterations (repeats) of the DNA sequence identifiction reaction, by which several genetic variations can be identified. ${ }^{4}$

Odds Ratio is a mathematical method to calculate the risk of disease conferred by genotypes. ${ }^{140}$

Software Jalview is a program for the $3 \mathrm{D}$ vizualisation of the secondary structure and the nucleic acid composition of a DNA sequence. 5

MDR (Multifactor dimensionality reduction software). MDR is a method used to detect gene-environment interactions, based on the dimension reduction to one size. One challenge in human genetics is identifying polymorphisms or DNA sequence variations which present a high risk of disease. In order to detect genotypes interactions, predictor genotypes are effectivley reduced from $\mathrm{N}$-dimensions to one dimension. ${ }^{141}$

\section{Conclusion}

The conclusion is that the clinical data, the biochemical and hematological laboratory investigations and the genetic variations of the 28 genes of interest: UCP2, UCP3, FABP2, PLIN1, PON1, FTO, ADRB3, BHMT2, MTHFR, IRS1, TRPM6, MT1A, APOA5, PEMT, ABCB4, CHDH, FADS2, PCYT1A, PCYT1B, PNPLA3, SCD, SCL44A1, STAT3, UBE2E2, ADAMTS9-AS2, KLHDC5, MEFV, MFE, INS, IGF2, ACE, TGF beta, HSPG Bam H1, sequenced by the Advanced NGx test and statistically interpreted by Jalview 2.8, MDR software version 3.0.2. programs, were correlated and they are associated with a high risk of developing metabolic syndrome. ${ }^{142-145}$

\section{Acknowledgments}

I wish to express my gratitude to all those people who provided qualified guidance and effective support in carrying out this study: Professor Tatiana Vassu-Dimov PhD, scientific coordinator of my doctoral thesis, Mr. Dănuț Gheorghe Cimponeriu, Professor at the Genetics Department of the Faculty of Biology, Bucharest University, Ms. Natalia Cucu Professor at the Genetics Department of the Faculty of Biology, Bucharest University, Ms. Ileana Stoica Professor at the Genetics Department of the Faculty of Biology, Bucharest University, Ms. Alexandra Simon Gruiță Professor at the Genetics Department of the Faculty of Biology, Bucharest University for allowing me to use the facilities of the Human Genetics Laboratory in conducting the genetic tests, Dr. Crăciun Anne Marie, who allowed me to use the biological samples of "N. Paulescu" Institute for Diabetes, Nutrition and Metabolic Diseases, Bucharest, and Dr. PopescuGuinea Gelu, head of the Diabetes, Nutrition and Metabolic Diseases Section within the Internal Diseases Department of Giurgiu County Emergency Hospital, who indicated to me the clinical criteria for the selection of patients with metabolic syndrome, obesity and diabetes mellitus, whose biological samples were investigated in the Clinical Bacteriology Laboratory of Giurgiu County Emergency Hospital under the guidance of Dr. Matefi Felicia, head of the laboratory, and Dr. Mihai Petre, Manager of Giurgiu County Emergency Hospital, who authorized my internship on a volunteer basis (Volunteering Contract no. $2 / 20.01 .2014$ ), thus enabling me to gather the biological material included in this study.

\section{Conflicts of interest}

Authors declare that there is no conflict of interest.

\section{References}

1. Cacabelos R, Fernandez-Novoa L, Lombardi V, et al. Molecular genetics of Alzheimer's disease and aging. Methods Find Exp Clin Pharmacol. 2005;27 Suppl A:1-573.

2. http://www.ebiotrade.com/buyf/productsf/qiagen/dneasy_tissue_system. htm.

3. Vassu-Dimov Tatiana, Csutak Ortansa, Stoica Ileana, e al. Genetica microorganismelor și inginerie genetică microbiană-Note de curs şi tehnici de laborator. Editura Petrion: Bucureşti; 2001.

4. Niculescu M. Advanced Nutrigenomics LLC; 2016.

5. Cole C, Barber JD, Barton GJ. The Jpred 3 secondary structure prediction server. Nucleic Acids Research. 2008;36(Web Server issue):W197-201

6. http://sourceforge.net/projects/mdr/.

7. Dean L, McEntyre JB. The Genetic Landscape of Diabetes. Bethesda (MD): National Center for Biotechnology Information (US); 2004.

8. http://ghr.nlm.nih.gov/gene/INS

9. Santoro N, Cirillo G, Amato A, et al. Insulin gene variable number of tandem repeats (INS VNTR) genotype and metabolic syndrome in childhood obesity. J Clin Endocr Metab. 2006;91(11):4641-4644.

10. Rodriguez S, Gaunt T, O'Dell S, et al. Haplotypic analyses of the IGF2INS-TH gene cluster in relation to cardiovascular risk traits. Hum Molec Genet. 2004;13(7):715-725.

11. Kalli KR, Conover CA. The insulin-like growth factor/insulin system in epithelial ovarian cancer. Front Biosci. 2003;8:d714-722.

12. Genatlas biochemistry entry for IGF2.

13. Insulin-Like Growth Factor 2 (Somatomedina A).

14. UniProt KB/Swiss-Prot:IGF2 HUMAN, P01344.

15. Cristea-Pop E, Popescu A, Truţia E, et al. Tratat de biochimie medical. Medicală: Bucureşti; 1991.

16. Miaoxin C, Macpherson A, Owens J, et al. Obesity alone or with type 2 diabetes is associated with tissue specific alterations in DNA methylation and gene expression of PPARGC1A and IGF2. Journal of Diabetes Research \& Clinical Metabolism. 2012;1:16.

17. Petry CJ, Seear RV, Wingate DL, et al. Associations between Paternally Transmitted Fetal IGF2 Variants and Maternal Circulating Glucose Concentration in Pregnancy. Diabetes. 2011;60(11):3090-3096. 
18. Cimponeriu D. Bazele genetice ale diabetului zaharat. Studii pe modele animale şi în populaţiile umane din România, Teză de doctorat, Universitatea din Bucureşti, Facultatea de Biologie; 2007.

19. Fuentes Calvo I, Martinez-Salgado C. TGF $\beta 1$. Atlas Genetics and Cytogenetics in Oncology and Haematology; 2013.

20. Transforming growth factor, BETA-1; TGFB1. *190180, OMIM.

21. Ken-ichi Aihara, Yasumasa Ikeda, Shusuke Yagi, et al. Transforming Growth Factor- $\beta 1$ as a Common Target Molecule for Development of Cardiovascular Diseases, Renal Insufficiency and Metabolic Syndrome. Cardiol Res Pract. 2010;2011:175381.

22. Lin X. Functions of heparan sulfate proteoglycans in cell signaling during Development. Development. 2005;131(24):6009-6021.

23. West L, Govindraj P, Koob TJ, et al. Changes in perlecan during chondrocyte differentiation in the fetal bovine rib growth plate. J Orthop Res. 2006;24(6):1317-1326.

24. Lander AD, Selleck SB. The Elusive Functions of Proteoglycans In Vivo Veritas. J Cell Biol. 2000;148(2):227-232.

25. Saved-Tabatabaei FA, Oostra BA, Isaacs A, et al. ACE polymorphisms Review Circulation Research. 2006;98(9):1123-1133.

26. Nawaz SK, Hasnain S. Pleiotropic efects of ACE polymorphism. Biochemia Medica. 2009;19(1):36-49.

27. Delanghe JR, Speeckaert MM, De Buyzere ML. COVID-19 infections are also affected by human ACE1 D/I polymorphism. Clin Chem Lab Med. 2020.

28. Hashimoto T, Perlot T, Rehman A, et al. ACE2 links amino acid malnutrition to microbial ecology and intestinal inflammation. Nature. 2012;487(7408):477-481.

29. Delanghe JR, Speeckaert MM, De Buyzere ML. The host's angiotensinconverting enzyme polymorphism may explain epidemiological findings in COVID-19 infections, 2020 Mar24. Clin Chim Acta. 2020;505:192193.

30. Cox R. Role of Fto gene in obesity revealed. Medical Research Council Harwell; 2016

31. Hussain M, Zahra SA, Ashfaq R. Structural Characterization of Arg322Gln Mutation in Fat Mass and Obesity Associated Protein. International Journal of Computational Bioinformatics and In Silico Modeling. 2014;3(5):466-472.

32. Coclitu C. FTO-Gena obezității. Revista studentiilor informati; 2007.

33. Spotol B, Mattace-Raso F, Sijbrands E, et al. The fat-mass and obesityassociated gene(FTO) predicts mortality in chronic kidney disease of various severity. Nephrol Dial Transplant. 2012;27 Suppl 4:iv58-62.

34. Freathy RM, Timpson NJ, Lawlor DA, et al. Common Variation in the FTO Gene Alters Diabetes- Related Metabolic Traits to the Extent Expected Given Its Effect on BMI. Diabetes. 2008;57(5):1419-1426.

35. Enquiries I. Obesity, Diabetes and Weight Loss. Genetic health Personal Health Management; 2016.

36. Zirk Kregor. Discover natural ability. Sports Gene; 2016.

37. Taylor MRG. The Pharmacogenetics of the human beta-adrenergic receptors. Pharmacogenetics J. 2007;7(1):29-37.

38. Dumitrache C. Endocrinologie... de la A la Z-dictionar encyclopedic. Editura Naţional: Bucureşti; 2008.

39. Restian A. Noutate editoriala: BAZELE MEDICINEI DE FAMILIE. ed. 3 , revizuita; 2013 .

40. http://www.uniprot.org
41. Esterbauer H, Schneitler C, Oberkofler H, et al. A common polymorphism in the promoter of UCP2 is associated with decreased risk of obesity in middle-aged humans. Nature Genet. 2001;28(2):178-183.

42. Bulotta A, Ludovico O, Coco A, et al. The common -866G/A polymorphism in the promoter region of the UCP-2 gene is associated with reduced risk of type 2 diabetes in Caucasians from Italy. $J$ Clin Endocr Metab. 2005;90(2):1176-1180.

43. Fisler JS, Warden $\mathrm{CH}$. Uncoupling proteins, dietary fat and the metabolic syndrome. Nutr Metab (Lond). 2006;3:38

44. Uncoupling Protein 3; UCP3. *602044, OMIM.

45. Russell AP, Schrauwen P, Somm E, et al. Decreased fatty acid beta-oxidation in riboflavin-responsive, multiple acylcoenzyme A dehydrogenase-deficient patients is associated with an increase in uncoupling protein-3. J Clin Endocr Metab. 2003;88(12):5921-5926.

46. Brown AM, Willi SM, Argyropoulos G, et al. A novel missense mutation, $\mathrm{R} 70 \mathrm{~W}$, in the human uncoupling protein 3 gene in a family with type 2 diabetes. Hum Mutat. 1999;13(6):506.

47. de Souza BM, Brondani LA, Bouças AP, et al. Associations between UCP1 -3826A/G, UCP2 -866G/A, Ala55Val and Ins/Del, and UCP3 $-55 \mathrm{C} / \mathrm{T}$ Polymorphisms and Susceptibility to Type 2 Diabetes Mellitus: Case-Control Study and Meta-Analysis. PLoS One; 2013.

48. Han TK. Effects Ala54Thr polymorphism of FABP2 on obesity index and biochemical variable in response to a aerobic exercise training. $J$ Exerc Nutrition Biochem. 2013;17(4):209-217.

49. http://www.genecards.org

50. https://www.ebi.ac.uk/interpro/entry/IPR031272

51. Abbas S, Raza TS, Ahmed F, et al. Association of Genetic polymorphism of PPARy-2, ACE, MTHFR, FABP-2 and FTO genes in risk prediction of type 2 diabetes mellitus. J Biomed Sci. 2013;20(1):80.

52. Turkovic LF, Pizent A, Dodig S, et al. FABP2 gene polymorphism and metabolic syndrome in elderly people of croatian descent. Biochem Med (Zagreb). 2012;22(2):217-224.

53. Bőhme M, Grallert H, Klapper M, et al. Association between functional FABP2 promoter haplotypes and body mass index analyses of 8072 participants of the KORA cohort study. Mol Nutr Food Res. 2009;53(6):681-685.

54. Ríos-González BE, Ibarra-Cortés B, Ramírez-López G, et al. Association of Polymorphisms of Genes Involved in Lipid Metabolism with Blood Pressure and Lipid Values in Mexican Hypertensive Individuals. Disease Markers. 2014;2014:150358.

55. Chang MH, Yesupriya A, Ned RM, et al. Genetic variants associated with fasting blood lipids in the U.S. population: Third National Health and Nutrition Examination Survery. BMC Med Genet. 2010;11:62.

56. http://www.rcsb.org/pdb

57. Lu X, Gruia-Gray J, Copeland NG, et al. The murine perilipin gene: the lipid droplet-associated perilipins derive from tissue-specific, mRNA splice variants and define a gene family of ancient origin. Mammalian Genome. 2001;12(9):741-749.

58. Ordovas JM, Corella D. Metabolic syndrome pathophysiology: the role of adipose tissue. Kidney Int Suppl. 2008;111:S10-S14.

59. Ordovás JM, Smith CE. PLIN1 gene: fat keeper and prevention switcher. $J$ Appl Physiol. 2010;108(3):477-478.

60. Ruiz JR, Larrarte E, Margareto J, et al. Preliminary findings on the role of PLIN1 polymorphisms on body composition and energy metabolism response to energy restriction in obese women. $\mathrm{Br} J$ Nutr. 2011;106(4):486-490 
61. Harel M, Aharoni A, Gaidukov L, et al. Structure and evolution of the serum paraoxonase family of detoxifying and anti-atherosclerotic enzymes. Nature Structural \& Molecular Biology. 2004;11(5):412-419.

62. Ceron JJ, Tecles F, Tvarijonaviciute A. Serum paraoxonase 1 (PON1) measurement: an update. BMC Vet Res. 2014;10:74.

63. Cherry N, Mackness M, Durrington P, e al. Paraoxonase (PON1) polymorphisms in farmers attributing ill health to sheep dip. Lancet. 2002;359(9308):763-764.

64. Kao YL, Donaghue K, Chan A, et al. A variant of paraoxonase (PON1) gene is associated with diabetic retinopathy in IDDM. J Clin Endocr Metab. 1998;83(7):2589-2592.

65. Barbieri M, Bonafe M, Marfella R, et al. LL-paraoxonase genotype is associated with a more severa degree of homeostasis model assessment IR in healthy subjects. J Clin Endocrinol Metab. 2002;87(1):222-225.

66. Ergun MA, Yurtcu E, Demirci H, et al. PON1 55 and 192 gene polymorphisms in type 2 diabetes mellitus patients in a Turkish population. Biochem Genet. 2011;49(1-2):1-8.

67. Mohammed Bakhit D, Mohammed Al-N, Vigilla MGB, et al. The PON is a susceptibility gene for hypertension. FASEB J. 2010;24(1 Suppl):524.

68. Szegedi SS, Castro CC, Koutmos M, et al. Betaine-homocysteine S-methyltransferase-2 is a methyltransferase S-methylmethioninehomocysteine. J Biol Chem. 200;283(14):8939-8945.

69. Li F, Feng Q, Lee C, et al. Human Betaine-Homocysteine Methyltransferase(BHMT) and BHMT2:Common Gene Sequence Variation and Functional Characterization. Mol Genet Metab. 2008;94(3):326-335.

70. Giusti B, Saracini C, Bolli P, et al. Blood Coagulation, Fibrinolysis and Cellular Haemostasis Early-onset ischaemic stroke: Analysis of 58 polymorphisms in 17 genes involved in methionine metabolism. Thromb Haemost. 2010;104(02):231-242.

71. Goyette P, Sumner JS, Milos R, et al. Human methylenetetrahydrofolate reductase: isolation of cDNA, mapping and mutation identification. Nature Genet. 1994;7:195-200.

72. Soerries S. What is an MTHFR Mutation? Katie-Wellness Mama; 2017.

73. Carnahan J. 10 Health Tips for Anyone with a MTHFR Gene Mutation. JillCarnahan.Com; 2014.

74. Ledowsky C. MTHFR Testing -How do I test for MTHFR. MTHFR SUPORT: Australia; 2017.

75. Găman V, Dobreanu M, Stan NM. Ghid practic de hematologie medicală. OBBCSSR-București; 2016.

76. Qian X, Lu Z, Tan M, et al. A meta-analysis of association between C677T polymorphism in the methylenetetrahydrofolate reductase gene and hypertension. Europ J Hum Genet. 2007;15(12):1239-1245.

77. Roffeei SN, Mohamed Z, Reynolds GP, et al. Association of FTO, LEPR and MTHFR gene polymorphisms with metabolic syndrome in schizophrenia patients receiving antipsychotics. Pharmacogenomics. 2014;15(4):477-485.

78. Jeste DV, Lieberman JA, Fassler D, et al. Diagnostic and Statistical Manual of Mental Disorders. 5th ed. American Psychiatric Publishing: Washington, DC London, England; 2013.

79. Alina AS, Cucu N. Studiul factorilor de risc în Boala Alzheimer. Lucrare de disertație Universitatea din Bucuresti, Facultatea de Biologie, Masterul de Biotehnologie Microbiană și Genetică; 2013.

80. Liu Z, Patil IY, Jiang T, et al. High-fat diet induces hepatic insulin resistance and impairment of synaptic plasticity. PLoS One. 2015;10(5):e0128274.
81. Hribal ML, Federici M, Porzio O, et al. The gly-to-arg(972) amino acid polymorphism in insulin receptor substrate-1 affects glucose metabolism in skeletal muscle cells. J Clin Endocr Metab. 2000;85(5):2004-2013.

82. Dziwura J, Bińczak-Kuleta A, Miazgowski T, et al. The associations between G972R polymorphism of the IRS-1 gene, insulin resistance, salt sensitivity and non-dipper hypertension. Hypertens Res. 2011;34(10):1082-1086.

83. Qi Q, Xu M, Wu H, et al. IRS1 Genotype Modulates Metabolic Syndrome Reversion in Response to 2-Year Weight-Loss Diet Intervention: The POUNDS LOST trial. Diabetes Care. 2013;36(11):3442-3447.

84. Song Y, Hsu YH, Niu T, et al. Common genetic variants of the ion channel transient receptor potential membrane melastatin 6 and 7 (TRPM6 and TRPM7), magnesium intake, and risk of type 2 diabetes in women. $B M C$ Med Genet. 2009; 10:4.

85. Blanchard MG, de Baaij JHF, Verkaart SAJ, et al. Flavaglines Stimulate Transient Receptor Potential Melastatin Type 6 (TRPM6) Channel Activity. PLoS One. 2015;10(3):e0119028.

86. Nair AV, Hocher B, Verkaart S, et al. Loss of insulin-induced activation of TRPM6 magnesium channels results in impaired glucose tolerance during pregnancy. Proc Natl Acad Sci U S A. 2012;109(28):11324-11329.

87. Kozarova R, Postadzhiyan A, Apostolova MD. Association of +1245 A/G MT1A and -209 A/G MT2A Polymorphysms with Coronary Artery Disease and Diabetes Mellitus in Bulgarian Cohort. Biotechnology \& Biotechnological Equipment. 2012;26(sup1):100-106.

88. Masters BA, Kelly EJ, Quaife CJ, et al. Targeted disruption of metallothionein I and II genes increases sensitivity to cadmium. Proc Nat Acad Sci. 1994;91(2):584-588.

89. Giacconi R, Bonfigli AR, Testa R, et al. $+647 \mathrm{~A} / \mathrm{C}$ and +1245 MT1A polymorphisms in the susceptibility of diabetes mellitus and cardiovascular complications. Mol Genet Metab. 2008;94(1):98-104.

90. Nduhirabandi F, du Toit FE, Lochner A. Melatonin and the metabolic syndrome: a tool for effective therapy in obesity-associated abnormalities? Acta Physiol (Oxf). 2012;205(2):209-223.

91. APOLIPOPROTEIN A-V; APOA5. OMIM: *606368.

92. Zhu WF, Wang CL, Liang L, et al. Triglyceride-raising APOA5 genetic variants are associated with obesity and non-HDL-C in Chinese children and adolescents. Lipids Health Dis. 2014;13:93.

93. Ouatou S, Ajjemami M, Charoute H, et al. Association of APOA5 rs662799 and rs3135506 polymorphisms with arterial hypertension in Moroccan patients. Lipids Health Dis. 2014;13:60.

94. Abdolkarim M, Mehryar Z, Vahid A, et al. Association of ApoA5 Gene Promoter Region-1131T $>$ C Polymorphism (rs662799) to Plasma Triglyceride Level in Patients with Type 2 Diabetic Nephropathy. J Clin Diagn Res. 2016;10(5):BC09-13.

95. Vance DE. Phospholipid methylation in mammals: from biochemistry to physiological function. Biochim Biophys Acta. 2014;1838(6):1477-1487.

96. Yamaoka K, Tango T. Effects of lifestyle modification on metabolic syndrome: a systematic review and meta-analysis. $B M C$ Med. 2012;10:138

97. Chen L, Chen YM, Wang LJ, et al. Higher homocysteine and lower betaine increase the risk of microangiopathy in patients with diabetes mellitus carrying the GG genotype of PEMT G774C. Diabetes Metab Res Rev. 2013;29(8):607-617.

98. Hochrath K, Krawczyk M, Goebel R, et al. The hepatic phosphatidylcholine transporter ABCB4 as modulator of glucose homeostasis. FASEB J 2012;26(12):5081-5091. 
99. Kimura Y, Morita S, Matsuo M, et al. Mechanism of multidrug recognition by MDR1/ABCB1. Cancer Sci. 2007;98(9):1303-1310.

100. Cotterill S. $A B C B 4$. Cancer Genetics Web; 2017.

101. Lei Z, Yao-Zhen P, Ling C, et al. Prevalence of ABCB4 polymorphisms in gallstone disease in han-Chinese population. Am J Transl Res. 2016;8(2):1218-1227.

102. Corbin KD, Abdelmalek MF, Spencer MD, et al. Genetic signatures in choline and 1-carbon metabolism are associated with the severity of hepatic steatosis. FASEB J. 2013;27(4):1674-1689.

103. Corbin KD, da Costa KA, Sha W, et al. Single nucleotide polymorphisms affecting phosphatidylcholine transport are associated with obesity. FASEB J. 2011; 25(1):585.

104. Huret J. CHDH (choline dehydrogenase). Atlas of Genetics and Cytogenetics in Oncology and Haematology; 2016.

105. Hartiala JA, Tang WHW, Wang Z, et al. Genome-wide association study and targeted metabolomics identifies sex-specific association of CPS1 with coronary artery disease. Nat Commun. 2016;7:10558.

106. Kumar J, Garg G, Kumar A, et al. Metabolism Pathway Genes Association of CHDH A119C and MTHFR C677T with Hyperhomocysteinemia. Circ Cardiovasc Genet. 2009;2(6):599-606.

107. Ganesh C, Ismeet K, Rubina T, et al. Common Variants of Homocysteine Metabolism Pathway Genes and Risk of Type 2 Diabetes and Related Traits in Indians. Exp Diabetes Res. 2012;2012:960318.

108. Vaittinen M, Walle P, Kuosmanen E, et al. FADS2 genotype regulates delta- 6 desaturase activity and inflammation in human adipose tissue. $J$ Lipid Res. 2016;57(1):56-65.

109. Li SW, Wang J, Yang Y, et al. Polymorphisms in FADS1 and FADS2 alter plasma fatty acids and desaturase levels in type 2 diabetic patients with coronary artery disease. Journal of Translational Medicine. 2016;14:79.

110. Marrachelli V, Monleon D, Morales JM, et al. Integrated snp analysis and metabolomic profiles of metabolic syndrome. J Hypertens. 2015;33(Suppl 1):e80.

111. Drews K, Różycka A, Barlik M, et al. Polymorphic variants of genes involved in choline pathway and the risk of intrauterine fetal death. Ginekol Pol. 2017;88(4):205-211.

112. Testa F, Filippelli M, Brunetti-Pierri R, et al. Mutations in the PCYT1A gene is responsible for isolated forms of retinal dystrophy. Eur J Hum Genet. 2017;25(5):651-655.

113. Payne F, Lim K, Girousse A, et al. Mutations disrupting the Kennedy phosphatidylcholine pathway in humans with congenital lipodystrophy and fatty liver disease. Proc Natl Acad Sci U S A. 2014;111(24):89018906.

114. Lykidis A, Murti KG, Jackowski S. Cloning and characterization of a second human CTP: phosphocholine cytidylyl transferase. J Biol Chem. 1998;273(22):14022-14029.

115. Watt KD. Metabolic syndrome: is immunosuppression to blame? Liver Transpl. 2011;17 Suppl 3:S38-S42.

116. Wilson PA, Gardner SD, Lambie NM, et al. Characterization of the human patatin-like phospholipase family. J Lipid Res. 2006;47(9):1940-1949.

117. Boursier J, Diehl AM. Patatin-like phospholipase domain-containing protein 3 and Liver Disease: Opportunities to Unravel Mechanisms Underlying Statistical Associations. Hepatology. 2015;61(1):18-20.

118. Maglio C, Pirazzi C, Pujia A, et al. The PNPLA3 I148M variant and chronic liver disease: When a genetic mutation meets nutrients. Food Research International. 2014;63:239-243.
119. Aragonès G, Auguet T, Armengol S, et al, PNPLA3 Expression Is Related to Liver Steatosis in Morbidly Obese Women with Non-Alcoholic Fatty Liver. Int J Mol Sci. 2016;17(5):630.

120. Thon M, Hosoi T, Chea C, et al. Loss of Stearoyl-CoA Desaturase-1 Activity Induced Leptin Resistance in Neuronal Cells. Biol Pharm Bull. 2017;40(8):1161-1164.

121. Ntambi JM. Regulation of stearoyl-CoA desaturase by polyunsaturated fatty acids and cholesterol. Journal of Lipid Research. 1999;40(9):15491558

122. Martin-Nunez GM, Cabrera-Mulero R, Rojo-Martinez G, et al. Polymorphisms in the SCD1 gene are associated with indices of stearoyl CoA desaturase activity and obesity: A prospective study. Mol Nutr Food Res. 2013;57(12):2177-2184.

123. Michel V, Bakovic M. The ubiquitous choline transporter SLC44A1. Cent Nerv Syst Agents Med Chem. 2012;12(2):70-81.

124. Traiffort E, O'Regan S, Ruat M. The choline transporter-like family SLC44: properties and roles in human diseases. Mol Aspects Med. 2013;34(2-3):646-654

125. Schenkel LC. Choline Transport and Metabolism in Genetically Deficient and Chronic Disease States. By A Thesis presented to The University of Guelph In partial fulfilment of requirements for the degree of Doctor of Philosophy in Human Health and Nutritional Sciences Guelph, Ontario; 2014.

126. Cohen J, Wannissorn N. Natural STAT3 Inhibitors + Its Role in Gut Inflammation, Obesity\& Cancer. The Selfhacked book; 2016.

127. Hu T, Chopra R. 4ZIA Crystal Structure of STAT3 N-terminal domain. PDB, RCSB; 2015.

128. Phillips CM, Goumidi L, Bertrais S, et al. Dietary Saturated Fat Modulates the Association between STAT3 Polymorphisms and Abdominal Obesity in Adults. J Nutr. 2009;139(11):2011-2017.

129. Kazakova EV, Wu Y, Zhou Z, et al. Association Between UBE2E2 Variant rs7612463 and Type 2 Diabetes Mellitus in a Chinese Han Population. Acta Biochim Pol. 2015;62(2):241-245.

130. Lakbabi El Yaagoubi F, Charoute H, Morjane I, et al. Association analysis of genetic variants with metabolic syndrome components in the Moroccan population. Curr Res Transl Med. 2017;65(3):121-125.

131. Er-lin Song, Li Xing, Liang Wang, et al. LncRNA ADAMTS9-AS2 inhibits cell proliferation and decreases chemoresistance in clear cell renal cell carcinoma via the miR-27a-3p/FOXO1 axi. Aging (Albany NY). 2019;11(15):5705-5725.

132. Qiang Zhang, Ke-Hao Wu, Jing-Yang He, et al. Novel Common Variants Associated with Obesity and Type 2 Diabetes Detected Using a cFDR Method. Sci Rep. 2017;7:16397.

133. Tang R, Liu H, Yuan Y, et al. Genetic factors associated with risk of metabolic syndrome and hepatocellular carcinoma. Oncotarget. 2017;8(21):35403-35411.

134. Balkarli A, Akyol M, Tepeli E, et al. MEFV gene variation R202Q is associated with metabolic syndrome. Eur Rev Med Pharmacol Sci. 2016;20(15):3255-3261.

135. www.ncbi.nlm.nih.gov/gene/3077

136. Datz C, Felder TK, Niederseer D, et al. Iron homeostasis in the Metabolic Syndrome. Eur J Clin Invest. 2013;43(2):215-224.

137. Dong C, Zhou H, Shen C, e al. Role of peroxisome proliferator- activated receptors gene polymorphisms in type 2 diabetes and metabolic syndrome. World J Diabetes. 2015;6(4):654-661 
138. Balasubramaniam S, Lewis B, Greed L, et al. Heterozygous Monocarboxylate Transporter 1(MCT1, SLC16A1) Deficiency as a Cause of Recurrent Ketoacidosis. JIMD Rep. 2016;29:33-38.

139. Al-Khawaga S, AlRayahi J, Saraswathi S, et al. A SLC16A1 Mutation in an Infant with Ketoacidosis and Neuroimaging Assessment: Expanding the Clinical Spectrum of MCT1 Deficiency. Front Pediatr. 2019;7:299.

140. Simon-Gruiţă A. Introducere în genetica populaţilor. Ed. Universităţii București; 2007.

141. Hahn LW, Ritchie MD, Moore JH. Multifactor Dimensionality Reduction software detecting gene-gene and gene-environment interactions. Bioinformatics. 2003;19(3):376-382.
142. Shen $\mathrm{Y}$, Wen $\mathrm{Z}$, Wang $\mathrm{N}$, et al. Investigation of Variants in UCP2 in Chinese Type 2 Diabetes and Diabetic Retinopathy. PLoS One. 2014;9(11): e112670

143. The Genetic Landscape of Diabetes. The Insulin Hormone (INS); 2004.

144. http://www.omim.org

145. https://en.wikipedia.org/wiki/Perlecan/ 